\title{
Analytic Hierarchy Process and Expert Choice: Benefits and Limitations
}

\author{
Alessio Ishizaka and Ashraf Labib \\ University of Portsmouth, Portsmouth Business School, Richmond Building, Portland \\ Street, Portsmouth PO1 3DE, United Kingdom \\ Alessio.Ishizaka@port.ac.uk \\ Ashraf.Labib@port.ac.uk
}

\begin{abstract}
.
This paper describes the original Analytic Hierarchy Process (AHP) as it is implemented in the software package Expert Choice. We demonstrate its application through a practical example. In particular, we discuss problem modelling, pairwise comparisons, judgement scales, derivation methods, consistency indices, synthesis of the weights and sensitivity analysis. Finally, the limitations of the original AHP along with the new proposed development are explained.
\end{abstract}

Keywords: AHP, Decision making, Review

\section{Introduction}

The Analytic Hierarchy Process (AHP) is a multi-criteria decision making (MCDM) method that helps the decision-maker facing a complex problem with multiple conflicting and subjective criteria (e.g. location or investment selection, projects ranking, and so forth). Several papers have compiled the AHP success stories in very different fields (Zahedi 1986; Golden, Wasil et al. 1989; Shim 1989; Vargas 1990; Saaty and Forman 1992; Forman and Gass 2001; Kumar and Vaidya 2006; Omkarprasad and Sushil 2006; Ho 2008; Liberatore and Nydick 2008). The oldest reference we have found dates from 1972 (Saaty 1972). After this, a paper in the Journal of Mathematical Psychology (Saaty 1977) precisely described the method. The vast majority of the applications still use AHP as described in this first publication and are unaware of successive developments. This fact is probably due to the leading software supporting AHP, namely, Expert Choice (http://www.expertchoice.com/), which still incorporates AHP as it was described in its first publication. In this paper, we describe AHP through Expert Choice and provide a sketch of the major directions in methodological developments (as opposed to a discussion of applications) and the further research in this important field.

\section{The original AHP method}

Like several other MCDM methods such as ELECTRE, MacBeth, SMART, PROMETHEE, UTA, etc (Belton and Stewart 2002; Figueira, Greco et al. 2005)), AHP is based on four steps: problem modelling, weights valuation, weights aggregation and 
[Preprint version] Please cite as "Ishizaka Alessio, Labib Ashraf, Analytic Hierarchy Process and Expert Choice: Benefits and Limitations, ORInsight, 22(4), p. 201-220, 2009"

sensitivity analysis. In the next sections we will review these four steps used by AHP and its evolutions based on a simple problem: the selection of a car to buy.

\subsection{Problem modelling}

As with all decision-making processes, the facilitator will sit a long time with the decision-maker(s) to structure the problem, which can be divided into three parts: goal (buy a car), criteria (initial cost, maintenance cost, prestige, quality and its sub-criteria) and alternatives (Fiat Uno, Nissan Maxima 4 Doors, Mercedes Benz 290, Volvo 840, Ford Fiesta) (figure 1). AHP has the advantage of permitting a hierarchical structure of the criteria, which provides users with a better focus on specific criteria and sub-criteria when allocating the weights.

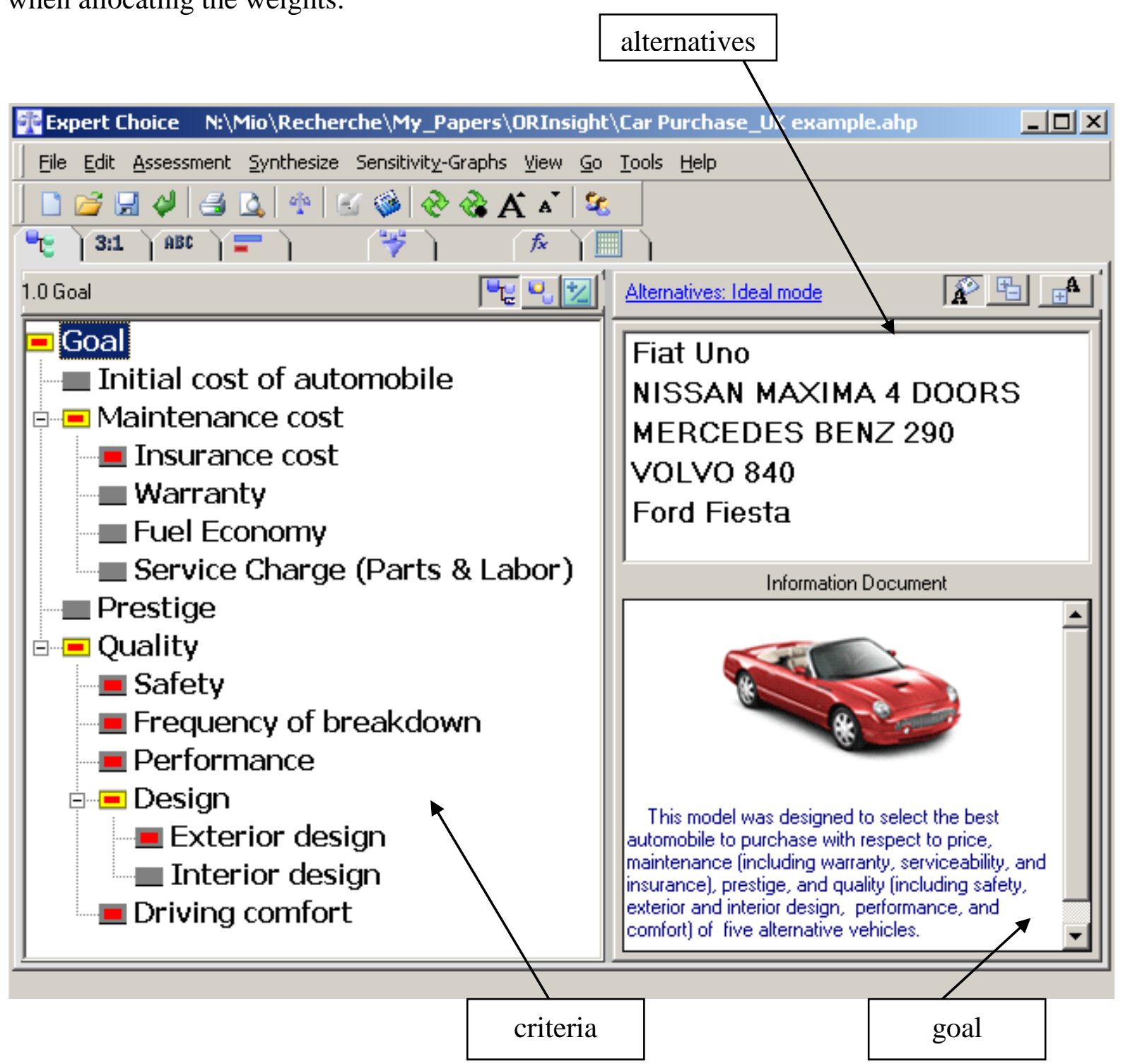

Figure 1: Example of hierarchy 
[Preprint version] Please cite as "Ishizaka Alessio, Labib Ashraf, Analytic Hierarchy Process and Expert Choice: Benefits and Limitations, ORInsight, 22(4), p. 201-220, 2009"

\subsection{Pairwise comparisons}

At each node of the hierarchy, a matrix will collect the pairwise comparisons of the decision-maker (e.g. figure 2).

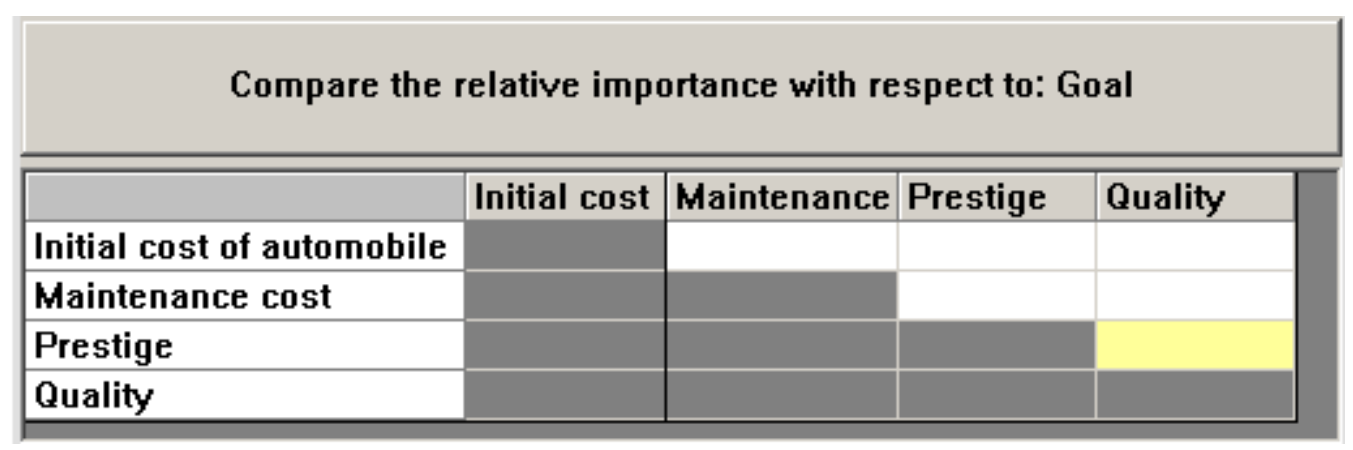

Figure 2: Comparison matrix of the first node

Psychologists argue that it is easier and more accurate to express one's opinion on only two alternatives than simultaneously on all the alternatives. It also allows consistency and cross checking between the different pairwise comparisons (see section 2.5). AHP uses a ratio scale, which, contrary to methods using interval scales (Kainulainen, Leskinen et al. 2009), requires no units in the comparison. The judgement is a relative value or a quotient $a / b$ of two quantities $a$ and $b$ having the same units (intensity, meters, utility, etc). The decision maker does not need to provide a numerical judgement; instead a relative verbal appreciation, more familiar in our daily lives, is sufficient.

If the matrix is perfectly consistent, then the transitivity rule (1) holds for all comparisons $a_{i j}$ :

$$
a_{i j}=a_{i k} \cdot a_{k j}
$$

For example, if team A beats team B two-zero and team B beats team C three-zero, then it is expected with the transitivity rule (1) that team A beats team C six-zero $(3 \cdot 2=6)$. However, this is seldom the case because our world is inconsistent by nature. As a minimal consistency is required to derive meaningful priorities, a test must be done (see section 2.5). Webber et al. (1996) state that the order in which the comparisons are entered in the matrix may affect the successive judgments.

\subsection{Judgement scales}

One of AHP's strengths is the possibility to evaluate quantitative as well as qualitative criteria and alternatives on the same preference scale of nine levels. These can be numerical (figure 3), verbal (figure 4) or graphical (figure 5). 
[Preprint version] Please cite as "Ishizaka Alessio, Labib Ashraf, Analytic Hierarchy Process and Expert Choice: Benefits and Limitations, ORInsight, 22(4), p. 201-220, 2009"

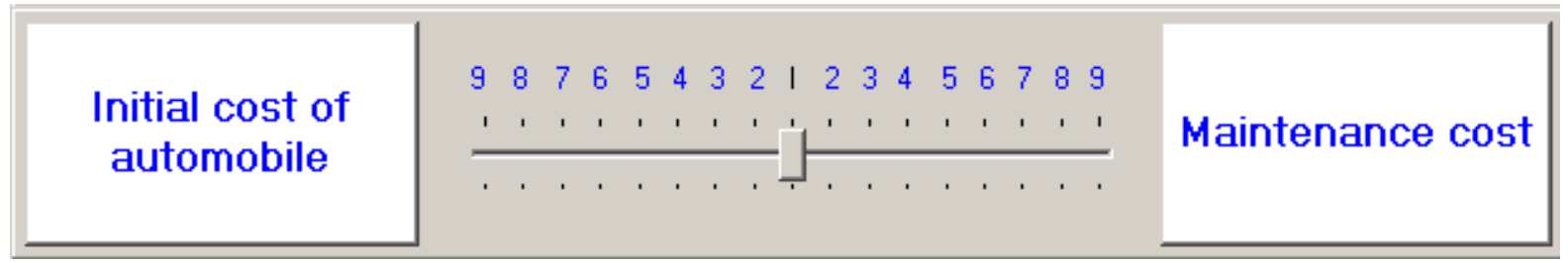

Figure 3: Numerical scale

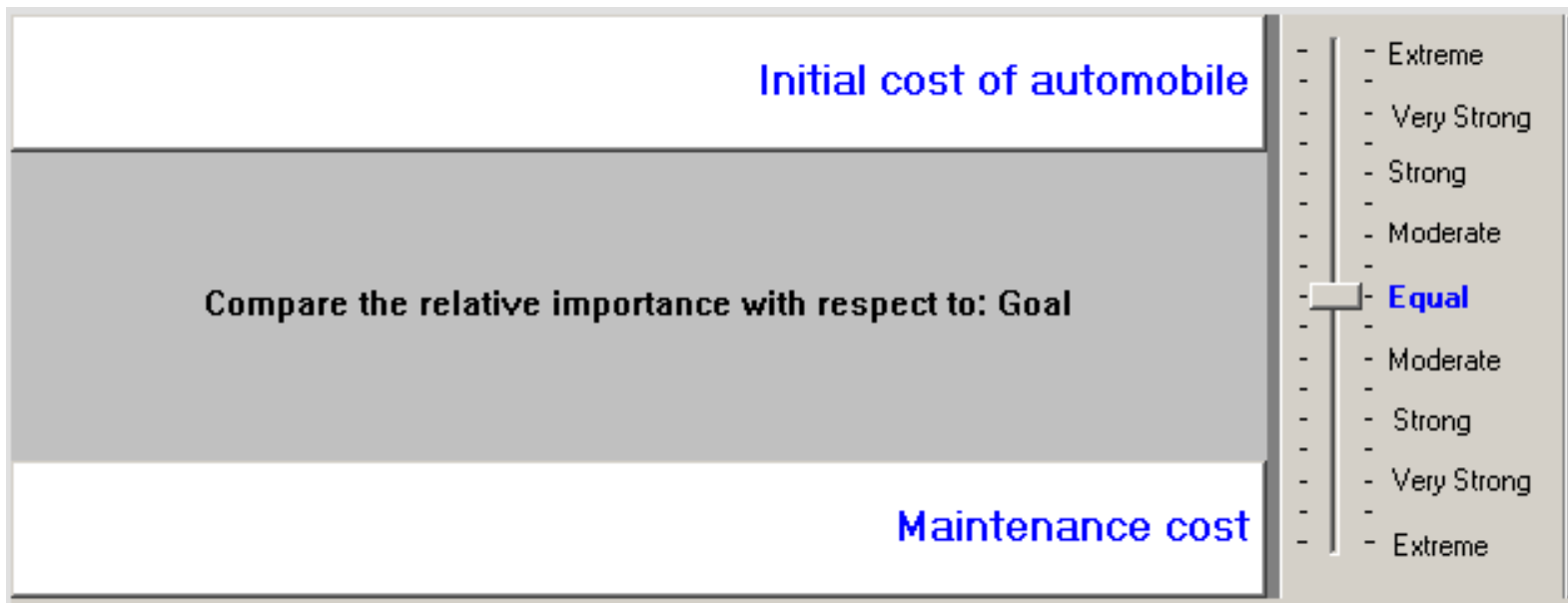

Figure 4: Verbal scale

\section{Initial cost of automobile}

\begin{tabular}{|l|}
\hline Compare the relative importance with respect to: Goal \\
\hline Maintenance cost \\
\hline
\end{tabular}

Figure 5: Graphical scale

\subsection{Priorities derivation}

Once the comparisons matrices are filled, priorities can be calculated. The traditional AHP uses the eigenvalue method. For some users this method seems quite obscure. In order to explain it, we start from the case of a consistent matrix with known priorities $p_{i}$. In this case, the comparison of the alternatives $i$ and $j$ is given by $p_{i} / p_{j}$, which multiplied by the priority vector $\vec{p}$ results in: 


$\left.\begin{array}{|c|c|c|c|}\hline p_{1} / p_{1} & p_{1} / p_{2} & \ldots & p_{1} / p_{n} \\ \hline p_{2} / p_{1} & p_{2} / p_{2} & \ldots & p_{2} / p_{n} \\ \hline \ldots & \ldots & \ldots & \ldots \\ \hline p_{n} / p_{1} & p_{n} / p_{2} & \ldots & p_{n} / p_{n}\end{array}\right]\left[\begin{array}{c}p_{1} \\ p_{2} \\ \ldots \\ p_{n}\end{array}\right]=n\left[\begin{array}{c}p_{1} \\ p_{2} \\ \ldots \\ p_{n}\end{array}\right]$

or grouped:

$$
\mathbf{A} \vec{p}=n \vec{p}
$$

where $\vec{p}$ : vector of the priorities

$n:$ dimension of the matrix

A: comparison matrix

Equation (2) is the formulation of an eigenvector problem. The calculated priorities are exact for a consistent matrix. When slight inconsistencies are introduced, priorities should vary only slightly according to the perturbation theory (Saaty 2003).

\subsection{Consistency}

As priorities make sense only if derived from consistent or near consistent matrices, a consistency check must be applied. Saaty (1977) has proposed a consistency index (CI), which is related to the eigenvalue method:

$$
\begin{aligned}
& \mathrm{CI}=\frac{\lambda_{\max }-n}{n-1}, \\
& \text { where } \lambda_{\max }=\text { maximal eigenvalue }
\end{aligned}
$$

The consistency ratio, the ratio of $\mathrm{CI}$ and $\mathrm{RI}$, is given by:

$$
\mathrm{CR}=\mathrm{CI} / \mathrm{RI} \text {, }
$$

where $\mathrm{RI}$ is the random index (the average $\mathrm{CI}$ of 500 randomly filled matrices).

If $\mathrm{CR}$ is less than $10 \%$, then the matrix can be considered as having an acceptable consistency.

Saaty (1977) calculated the random indices shown in Table 1.

\begin{tabular}{|l|l|l|l|l|l|l|l|l|}
\hline$n$ & 3 & 4 & 5 & 6 & 7 & 8 & 9 & 10 \\
\hline RI & 0.58 & 0.9 & 1.12 & 1.24 & 1.32 & 1.41 & 1.45 & 1.49 \\
\hline
\end{tabular}

Table 1: Random indices from Saaty (1977)

Other researchers have run simulations with different numbers of matrices (Lane and Verdini 1989; Tummala and Wan 1994; Alonso and Lamata 2006) or incomplete matrices (Forman 1990). Their random indices are different but close to Saaty's. 


\subsection{Aggregation}

The last step is to synthesize the local priorities across all criteria in order to determine the global priority. The historical AHP approach (called later distributive mode) adopts an additive aggregation (5) with normalization of the sum of the local priorities to unity (figure 6):

$$
p_{i}=\sum_{j} w_{j} \cdot l_{i j}
$$

where $\quad p_{i}$ : global priority of the alternative $i$

$l_{i j}$ : local priority

$w_{j}$ : weight of the criterion $j$

The ideal mode uses a normalisation by dividing the score of each alternative only by the score of the best alternative under each criterion (figure 7).

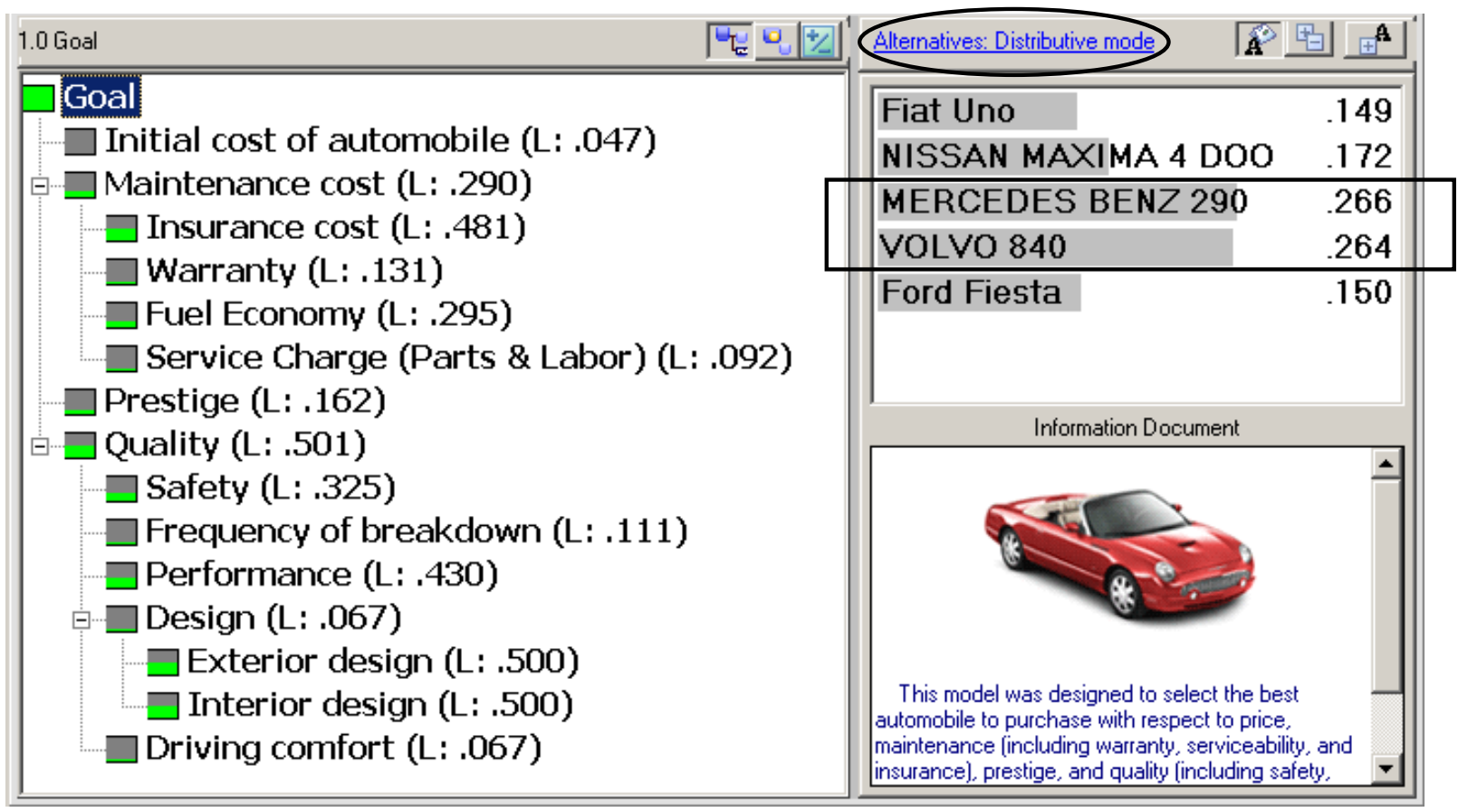

Figure 6: Priorities with the distributive mode 


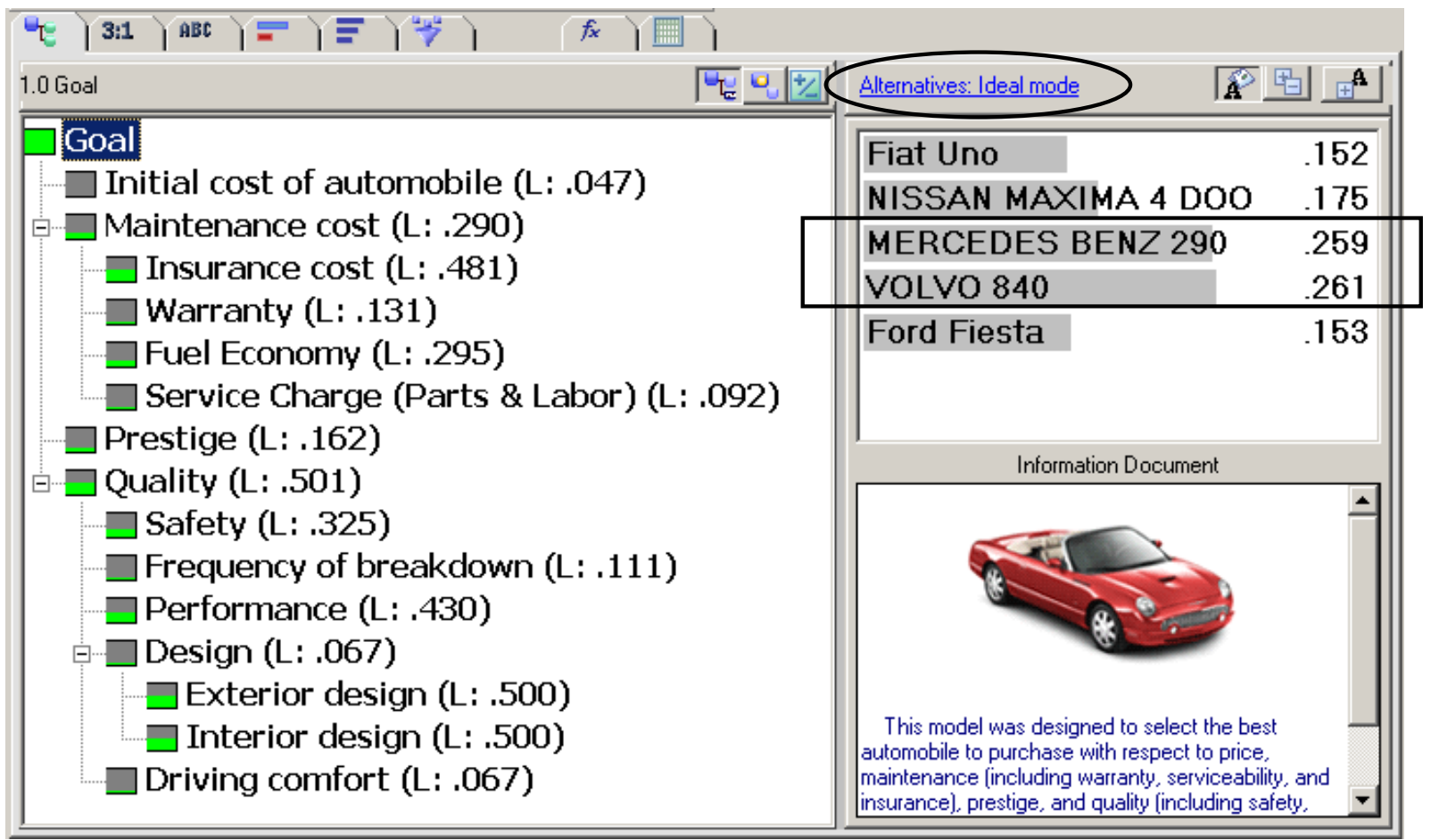

Figure 7: Priorities with the ideal mode

It can be seen that the two approaches do not necessarily recommend the same ranking (see the rectangles in figure 6 and 7).

If we already know the priorities, the distributive mode is the only approach that will retrieve these priorities. However if a copy (Belton and Gear 1983) or a near copy (Dyer 1990) of an alternative is introduce or removed (Troutt 1988), a rank reversal of the alternatives may appear. This phenomenon has been criticized from one side (Dyer 1990; Dyer 1990; Holder 1990; Holder 1991; Stam and Duarte Silva 2003) and legitimized by another (Saaty 1986; Harker and Vargas 1987; Harker and Vargas 1990; Saaty 1990; Saaty 1991; Saaty 1994; Pérez 1995; Saaty 2006). This rank reversal phenomenon is not unique to AHP but to all additive models (Triantaphyllou 2001; Wang and Luo 2009).

Millet and Saaty (2000) gave some guidance on which normalisation to use. If we are in a closed system (i.e. no alternative will be added or removed), then the distributive mode should be used. If we are in an open system (i.e. alternatives can be added or removed) and we allow our preferences for alternatives to be dependent on other alternatives (in other words, we accept the rank reversal phenomenon), then the distributive mode is indicated. If we are in an open system and you do not want that other alternatives to affect the outcome, then the ideal mode is recommended. Based on these observations, Expert Choice has been modified to support the two modes.

\subsection{Sensitivity analysis}

The last step of the decision process is the sensitivity analysis, where the input data are slightly modified in order to observe the impact on the results. If the ranking does not change, the results are said to be robust. The sensitivity analysis is best performed with an interactive graphical interface. Expert Choice allows different sensitivity analyses, where the main difference is the various graphical representations (figure 8). 


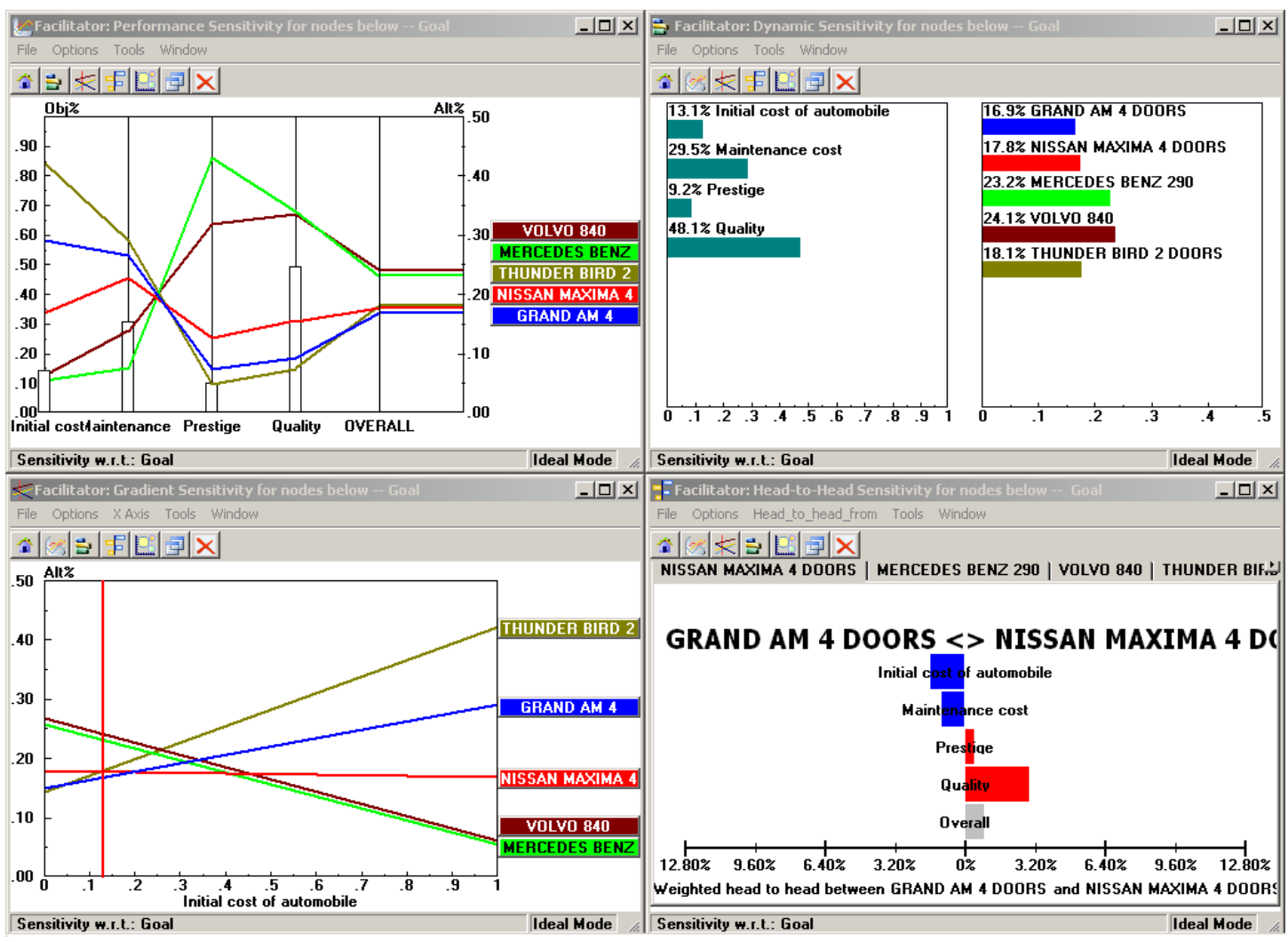

Figure 8: An example of four possible graphical sensitivity analyses in Expert Choice

\section{Limitations of the original AHP and Expert Choice}

\subsection{Problem structuring}

This step is important, because a different structure may lead to a different final ranking. Several authors (Stillwell, von Winterfeldt et al. 1987; Weber, Eisenführ et al. 1988; Pöyhönen, Hamalainen et al. 1997) have observed that criteria with a large number of subcriteria tend to receive more weight than when they are less detailed. Brugha (2004) has provided a complete guideline to structure a problem hierarchically. A book (Saaty \& Forman, 1992) compiling hierarchies in different applications has been written. When setting up the AHP hierarchy with a large number of elements, the decision maker should attempt to arrange these elements in clusters so they do not differ in extreme ways (Saaty 1991; Ishizaka 2004; Ishizaka 2004).

\subsection{Pairwise comparisons}

Comparisons are recorded in a positive reciprocal matrix, as in figure 2. In special cases, such as in currencies exchanges, not reciprocal matrices can be used (Hovanov, Kolari et al. 2008). Even if not reciprocal matrices are then treated similarly to traditional matrices, Expert Choice does not offer the possibility not to be reciprocal.

\subsection{Judgement scales}

The use of verbal comparisons is intuitively appealing, user-friendly and more common in our everyday lives than numbers. It may also allow some ambiguity in non-trivial 
comparisons. This ambiguity in the English language has also been criticised (Donegan, Dodd et al. 1992). Due to its pairwise comparisons AHP needs ratio scales. Barzilai (2005) claims that preferences cannot be represented with ratio scales, because in his opinion an absolute zero does not exists, as with temperature or electrical tension. Saaty (1994) states that ratio scales are the only possible measurement if we want to be able to aggregate measurement, as in a weighted sum. Dodd and Donegan (1995) have criticized the absence of a zero in the preference scale.

To derive priorities, the verbal comparisons must be converted into numerical ones. In Saaty's AHP the verbal statements are converted into integers from one to nine. Theoretically there is no reason to be restricted to these numbers and verbal gradation. If the verbal gradation has been little investigated, several other numerical scales have been proposed (table 2, figures 9 and 10). Harker and Vargas (1987) have evaluated a quadratic and a root square scale in only one simple example and argued in favour of Saaty's 1 to 9 scale.

However, one example seems not enough to conclude the superiority of the 1-9 linear scale. Lootsma (1989) argued that the geometric scale is preferable to the 1-9 linear scale. Salo and Hämäläinen (1997) point out that the integers from one to nine yield local weights, which are unevenly dispersed, so that there is lack of sensitivity when comparing elements, which are preferentially close to each other. Based on this observation, they propose a balanced scale where the local weights are evenly dispersed over the weight range [0.1, 0.9]. Earlier Ma and Zheng (1991) have calculated a scale where the inverse elements $x$ of the scale $1 / x$ are linear instead of the $x$ in the Saaty scale. Donegan et al. (1992) have proposed an asymptotic scale avoiding the boundary problem, e.g. if the decision-maker enters $a_{i j}=3$ and $a_{j k}=4$, s/he is forced to an intransitive relation (1) because the upper limit of the scale is 9 and s/he cannot enter $a_{i k}=12$. Ji and Jiang (2003) propose a mixture of verbal and geometric scales. The possibility to integrate negative values in the scale has been also explored (Saaty and Ozdemir 2003; Millet and Schoner 2005).

\begin{tabular}{|l|r|r|r|r|r|r|r|r|r|}
\hline \multicolumn{1}{|c|}{ Scale type } & \multicolumn{7}{|c|}{ Values } \\
\hline $\begin{array}{l}\text { Linear } \\
\text { (Saaty 1977) }\end{array}$ & 1 & 2 & 3 & 4 & 5 & 6 & 7 & 8 & 9 \\
\hline $\begin{array}{l}\text { Power } \\
\text { (Harker and Vargas 1987) }\end{array}$ & 1 & 4 & 9 & 16 & 25 & 36 & 49 & 64 & 81 \\
\hline $\begin{array}{l}\text { Geometric } \\
\text { (Lootsma 1989) }\end{array}$ & 1 & 2 & 4 & 8 & 16 & 32 & 64 & 128 & 256 \\
\hline $\begin{array}{l}\text { Logarithmic } \\
\text { (Ishizaka, Balkenborg et al. } \\
\text { 2006) }\end{array}$ & 1 & 1.58 & 2 & 2.32 & 2.58 & 2.81 & 3 & 3.17 & 3.32 \\
\hline $\begin{array}{l}\text { Root square } \\
\text { (Harker and Vargas 1987) }\end{array}$ & 0 & 0.12 & 0.24 & 0.36 & 0.46 & 0.55 & 0.63 & 0.70 & 0.76 \\
\hline $\begin{array}{l}\text { Asymptotical } \\
\text { (Dodd and Donegan 1995) }\end{array}$ & 1 & 1.13 & 1.29 & 1.5 & 1.8 & 2.25 & 3 & 4.5 & 9 \\
\hline $\begin{array}{l}\text { Inverse linear } \\
\text { (Ma and Zheng 1991) }\end{array}$ & 1 & 1.22 & 1.5 & 1.86 & 2.33 & 3 & 4 & 5.67 & 9 \\
\hline $\begin{array}{l}\text { Balanced } \\
\text { (Salo and Hamalainen } \\
\text { 1997) }\end{array}$ & & & & & & & & & 3 \\
\hline
\end{tabular}

Table 2: Different scales for comparing two alternatives 


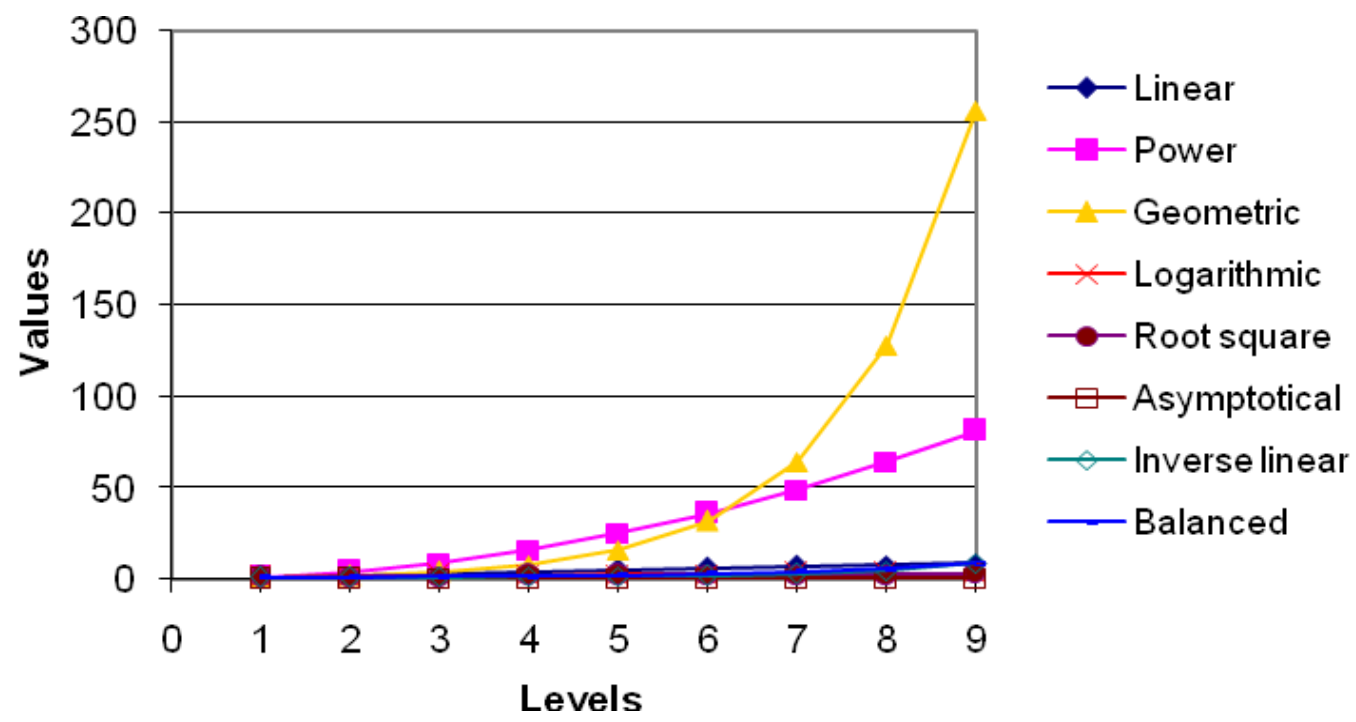

Figure 9: Graph of the judgement scales

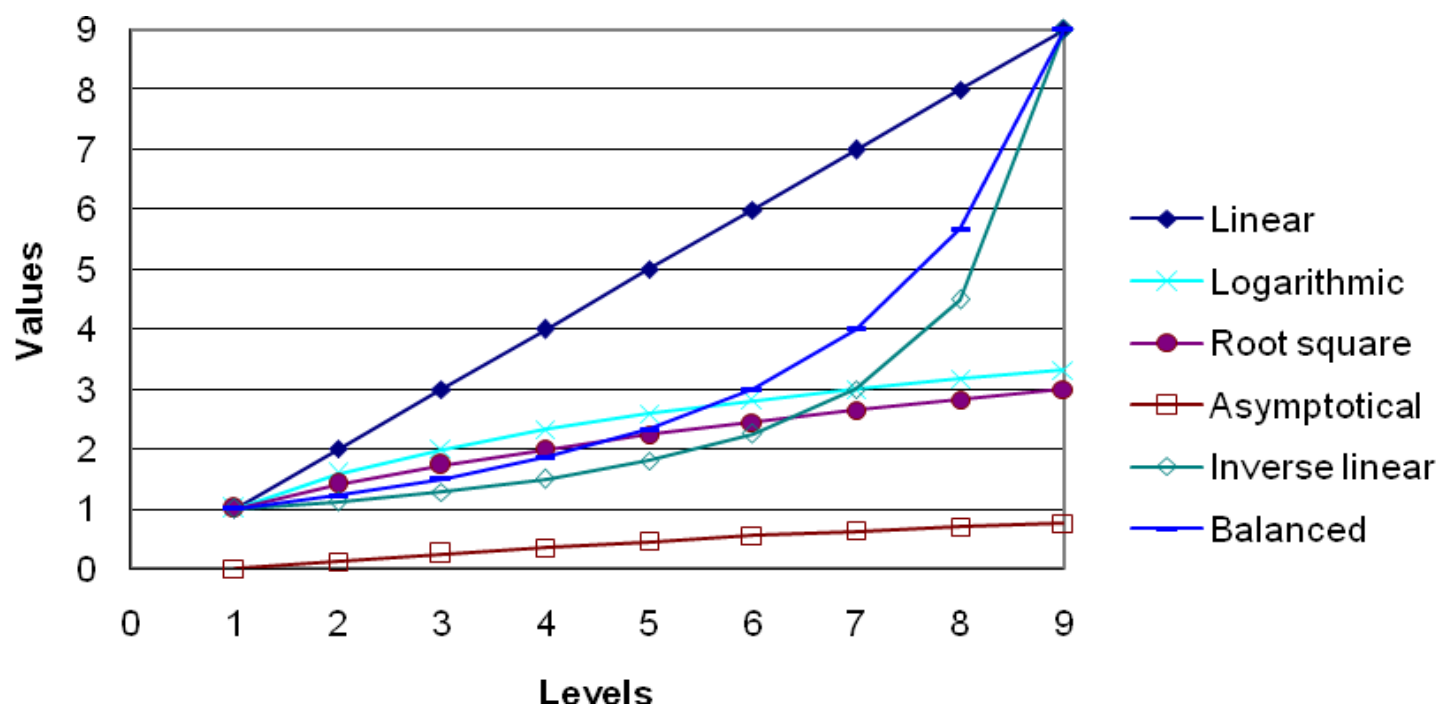

Figure 10: Graph of the judgement scales without the geometric and power scales.

Among all the proposed scales, the linear scale with the integers one to nine and their reciprocals has been used by far the most often in applications. It is also the only one implemented in Expert Choice. Saaty $(1980 ; 1991)$ advocates it as the best scale to represent weight ratios. However, the cited examples deal with objective measurable alternatives such as the areas of figures, whereas AHP mainly treats decision processes as subjective issues. We understand the difficulty of verifying the effectiveness of scales through subjective issues. Salo and Hämäläinen (1997) demonstrate the superiority of the balanced scale when comparing two elements. The choice of the "best" scale is a very heated debate. Some scientists argue that the choice depends on the person and the decision problem (Harker and Vargas 1987; Pöyhönen, Hamalainen et al. 1997). Therefore, we believe that other scales would be welcomed in Expert Choice. 


\subsection{Priorities derivation}

Only two years later than the publication of the original AHP, Johnson et al. (1979) show a rank reversal problem for scale inversion with the eigenvalue method. For example, consider the matrix of figure 11, asking which car is the most fuel economical. The calculated priorities are: $(0.061 ; 0.374 ; 0.134 ; 0.387 ; 0.043)$, with Volvo 840 being the winner.

\begin{tabular}{|l}
\begin{tabular}{|l|l|r|r|r|r|}
\hline Compare the relative preference with respect to: Maintenance cost & Fuel Economy \\
\hline \hline & Fiat Uno & NISSAN MAXIMA & MERCEDES BENZ & VOLVO 840 & Ford Fiesta \\
\hline Fiat Uno & & 7.0 & 2.0 & 8.0 & 2.0 \\
\hline NISSAN MAXIMA 4 DOORS & & & 3.0 & 1.0 & 8.0 \\
\hline MERCEDES BENZ 290 & & & & 4.0 & 5.0 \\
\hline VOLVO 840 & & & & & 5.0 \\
\hline Ford Fiesta & Incon: 0.04 & & & & \\
\hline
\end{tabular}
\end{tabular}

Figure 11: Comparison matrix

If we invert the question: which car has the highest fuel consumption, then the comparisons are simply inverted (figure 12$)$. The calculated priorities are: $(0.299 ; 0.047 ; 0.140 ; 0.051$; 0.462), with Nissan being the winner. We have a rank reversal due to the formulation of the problem (which is a different and independent cause of the rank reversal due to the introduction or deletion of an alternative).

Compare the relative preference with respect to: Maintenance cost | Fuel Consumption

\begin{tabular}{|l|l|r|r|r|r|}
\hline & Fiat Uno & NISSAN MAXIMA & MERCEDES BENZ & VOLVO 840 & Ford Fiesta \\
\hline Fiat Uno & & 7.0 & 2.0 & $\mathbf{8 . 0}$ & 2.0 \\
\hline NISSAN MAXIMA 4 D00RS & & & 3.0 & 1.0 & 8.0 \\
\hline MERCEDES BENZ 290 & & & & 4.0 & 5.0 \\
\hline VOLVO 840 & & & & & 5.0 \\
\hline Ford Fiesta & Incon: 0.04 & & & \\
\hline
\end{tabular}

Figure 12: Comparisons of figure 11 are inverted

In order to avoid this problem, Crawford and Williams (1985) have adopted another approach in minimizing the multiplicative error (3):

$$
\begin{aligned}
& a_{i j}=\frac{p_{i}}{p_{j}} e_{i j} \\
& \text { where } a_{i j} \text { is the comparison between object } i \text { and } j \\
& p_{i} \text { is the priority of object } i \\
& e_{i j} \text { is the error }
\end{aligned}
$$

The multiplicative error is commonly accepted to be log normal distributed (similarly the additive error would be assumed to be normal distributed). The geometric mean (7) will minimize the sum of these errors (8).

$$
p_{i}=\sqrt[n]{\prod_{j=1}^{n} a_{i j}}
$$




$$
\min \sum_{i=1}^{n} \sum_{j=1}^{n}\left(\ln \left(a_{i j}\right)-\ln \left(\frac{p_{i}}{p_{j}}\right)\right)^{2}
$$

The geometric mean (also sometimes known as Logarithmic Least Squares Method) can be easily calculated by hand and has been supported by a large segment of the AHP community (Budescu 1984; Fichtner 1986; Lootsma 1993; Lootsma 1996; Barzilai 1997; Barzilai and Lootsma 1997; Aguarón and Moreno-Jiménez 2000; Escobar and Moreno-Jiménez 2000; Aguarón and Moreno-Jiménez 2003; Leskinen and Kangas 2005). Its main advantage is the absence of rank reversals due to the right and left inconsistency, In fact geometric means of rows and columns provide the same ranking (which is not necessarily the case with the eigenvalue method).

If mathematical evidence points clearly to the geometric mean over the eigenvalue method, there is no clear differences between these two methods when simulations are applied (Budescu, Zwick et al. 1986; Golany and Kress 1993; Herman and Koczkodaj 1996; Cho and Wedley 2004; Jones and Mardle 2004; Ishizaka and Lusti 2006), apart from special cases (Bajwa, Choo et al. 2008). Perhaps in the light of this lack of practical evidence, Saaty's group has always supported the eigenvalue method (Saaty and Vargas 1984; Saaty and Vargas 1984; Harker and Vargas 1987; Saaty and Hu 1998; Saaty 2003).

Other methods have been proposed, each one based either on the idea of the distance minimisation (like the geometric mean) or on the idea that small perturbation inducing small errors (like the eigenvalue method or the arithmetic mean of rows). Cho and Wedley (2004) have enumerated 18 different methods, which are effectively 15 because three are equivalent to others (Lin 2007). However, Expert Choice incorporates only the eigenvalue method.

\subsection{Consistency}

Expert Choice uses the consistency ratio (4). However, this consistency ratio has been criticised because it allows contradictory judgements in matrices (Kwiesielewicz and van Uden 2004; Bana e Costa and Vansnick 2008) or rejects reasonable matrices (Karapetrovic and Rosenbloom 1999). Interactive techniques based on the transitivity rule (1) have been developed in order to discover contradictory judgements and correct them (Ishizaka and Lusti 2004; Wang, Chin et al. 2009). Their inclusion in Expert choice would be beneficial.

Several other methods have been proposed to measure consistency. Peláez and Lamata (2003) describe a method based on the determinant of the matrix. Crawford and Williams (1985) prefer to sum the difference between the ratio of the calculated priorities and the given comparisons. The transitivity rule (2) has been used by Salo and Hamalainen (1997) and later by Ji and Jiang (2003). Alonso and Lamata (2006) have computed a regression of the random indices and propose the formulation:

$$
\lambda_{\max }<n+0.1(1.7699 n-4.3513)
$$

Stein and Mizzi (2007) use the normalised column of the comparison matrix.

For all consistency checking, some questions remain: what is the cut-off rule to declare my matrix inconsistent? Should this rule depend on the size of the matrix? How should I adapt my consistency definition, when I use another judgement scale? 


\subsection{Aggregation}

The multiplicative aggregation (10) has been proposed to prevent the rank reversal phenomenon observed in the distributive mode (see section 2.6) (Lootsma 1993; Barzilai and Lootsma 1997).

$$
p_{i}=\prod_{j} l_{i j}{ }^{w_{j}}
$$

The multiplicative aggregation has non-linearity properties allowing a superior compromise to be selected, which is not the case with the additive aggregation (Stam and Duarte Silva 2003; Ishizaka, Balkenborg et al. 2006). However, Vargas (1997) showed that additive aggregation is the only way to retrieve exact weights of known objects. A multiplicative aggregation is not possible at the moment in Expert Choice.

\subsection{Sensitivity analysis}

The sensitivity analysis in Expert Choice varies the weights of the criteria as input data. It is also imaginable to have in future a sensitivity analysis by varying interactively the local priorities of the alternatives (there is no mathematical challenge in it).

However, sensitivity analysis is a fundamental process in the decision with AHP; it has received little attention from the academic literature.

\section{Conclusion and future developments}

Decisions that need support methods are difficult by definition and therefore complex to model. A trade-off between prefect modelling and usability of the model should be achieved. It is our belief that AHP has reached this compromise and will be useful for many other cases as it has been in the past. In particular, AHP has broken through the academic community to be widely used by practitioners. This widespread use is certainly due to its ease of applicability and the structure of AHP which follows the intuitive way in which managers solve problems. The hierarchical modelling of the problem, the possibility to adopt verbal judgements and the verification of the consistency are its major assets. Expert Choice, the user-friendly supporting software, has certainly largely contributed to the success of the method. It incorporates intuitive graphical user interfaces, automatic calculation of priorities and inconsistencies and several ways to process a sensitivity analysis. Today, several other supporting software packages have been developed: Decision Lens, HIPRE 3+, RightChoiceDSS, Criterium, EasyMind, WebAHP,... not to mention that a template in Excel could also be easily generated. However most of the software are based only on the classical AHP. Along with its traditional applications, a new trend, as compiled by the work of Ho (2008), is to use AHP in conjunction with others methods: mathematical programming techniques like linear programming, Data Envelopment Analysis (DEA), Fuzzy Sets, House of Quality, Genetic Algorithms, Neural Networks, SWOT-analysis, and recently with GIS (Temiz and Tecim 2009). There is little doubt that AHP will be more and more frequently adopted.

AHP still suffers from some theoretical disputes. The rank reversal is surely the most debated problem. This phenomenon is still not fully resolved and maybe it will never be because the aggregation of preferences transposed from scales of different units is not easily interpretable and even questionable according to the French school (Roy 1996). 
The assumption of criteria independence (no correlation) may be sometimes a limitation of AHP (and other MCDM methods). The Analytic Network Process (ANP), a generalisation of AHP with feed-backs to adjust weights, may be a solution. However the decision-maker must answer a much larger number of questions, which may be quite complex: e.g. "Given an alternative and a criterion, which of the two alternatives influences the given criterion more and how much more than another alternative" (Saaty and Takizawa 1986). A simplified ANP, while still keeping its proprieties, would be beneficial for a wider adoption of the method. Another direction of the research will probably be on a more soft side. The choice of a hierarchy and a judgement scale is important and difficult. Problem structuring methods could help in the construction of AHP hierarchies.

\section{Acknowledgement}

The authors would like to thank the anonymous reviewer for the valuable feedback and constructive criticism.

\section{References}

Aguarón, J. and J. Moreno-Jiménez (2000). "Local Stability Intervals in the Analytic Hierarchy Process." European Journal of Operational Research 125(1): 113-132.

Aguarón, J. and J. Moreno-Jiménez (2003). "The Geometric Consistency Index: Approximated Thresholds." European Journal of Operational Research 147(1): 137145.

Alonso, J. and T. Lamata (2006). "Consistency in the Analytic Hierarchy Process: a New Approach." International Journal of Uncertainty, Fuzziness and Knowledge-Based Systems 14(4): 445-459.

Bajwa, G., E. Choo, et al. (2008). "Effectiveness Analysis of Deriving Priority Vectors from Reciprocal Pairwise Comparison Matrices." Asia-Pacific Journal of Operational Research 25(3): 279-299.

Bana e Costa, C. and J. Vansnick (2008). "A Critical Analysis of the Eigenvalue Method Used to Derive Priorities in AHP." European Journal of Operational Research 187(3): 1422-1428.

Barzilai, J. (1997). "Deriving Weights from Pairwise Comparisons Matrices." Journal of the Operational Research Society 48(12): 1226-1232.

Barzilai, J. (2005). "Measurement and preference function modelling." International Transactions in Operational Research 12(2): 173-183.

Barzilai, J. and F. Lootsma (1997). "Power relation and group aggregation in the multiplicative AHP and SMART." Journal of Multi-Criteria Decision Analysis 6(3): 155-165.

Belton, V. and A. Gear (1983). "On a Shortcoming of Saaty's Method of Analytical Hierarchies." OMEGA 11(3): 228-230.

Belton, V. and T. J. Stewart (2002). Multiple Criteria Decision Analysis: An Integrated Approach, Kluwer Academic Publishers.

Brugha, C. (2004). "Structure of multi-criteria decision-making." Journal of the Operational Research Society 55(1): 1156-1168.

Budescu, D. (1984). "Scaling binary comparison matrices: A comment on Narasimhan's proposal and other methods." Fuzzy Sets and Systems 14(2): 187-192.

Budescu, D., R. Zwick, et al. (1986). "A comparison of the eigenvalue method and the geometric mean procedure for ratio scaling." Applied psychological measurement 10(1): 69-78. 
Cho, E. and W. Wedley (2004). "A Common Framework for Deriving Preference Values from Pairwise Comparison Matrices." Computers and Operations Research 31(6): 893-908.

Crawford G, W. C. (1985). "A Note on the Analysis of Subjective Judgement Matrices." Journal of Mathematical Psychology 29(4): 387-405.

Dodd, F. and H. Donegan (1995). "Comparison of priotization techniques using interhierarchy mappings." Journal of the Operational Research Society 46(4): 492498.

Donegan, H., F. Dodd, et al. (1992). "A new approach to AHP decision-making." The Statician 41(3): 295-302.

Dyer, J. (1990). "A clarification of "Remarks on the Analytic Hierarchy Process"." Management Science 36(3): 274-275.

Dyer, J. (1990). "Remarks on the Analytic Hierarchy Process." Management Science 36(3): 249-258.

Escobar, M. and J. Moreno-Jiménez (2000). "Reciprocal distributions in the analytic hierarchy process." European Journal of Operational Research 123(1): 154-174.

Fichtner, J. (1986). "On deriving priority vectors from matrices of pairwise comparisons." Socio-Economic Planning Sciences 20(6): 341-345.

Figueira, J., S. Greco, et al., Eds. (2005). Multiple Criteria Decision Analysis: State of the Art Surveys. New York, Springer-Verlag.

Forman, E. (1990). "Random Indices for Incomplete Pairwise Comparison Matrices." European Journal of Operational Research 48(1): 153-155.

Forman, E. and S. Gass (2001). "The Analytic Hierarchy Process - An Exposition." Operations Research 49(4): 469-486.

Golany, B. and M. Kress (1993). "A multicriteria evaluation of the methods for obtaining weights from ratio-scale matrices." European Journal of Operational Research 69(2): 210-202.

Golden, B., E. Wasil, et al. (1989). The Analytic Hierarchy Process: Applications and Studies. Heidelberg, Springer-Verlag.

Harker, P. and L. Vargas (1987). "The Theory of Ratio Scale Estimation: Saaty's Analytic Hierarchy Process." Management Science 33(11): 1383-1403.

Harker, P. and L. Vargas (1990). "Reply to "Remarks on the Analytic Hierarchy Process"." Management Science 36(3): 269-273.

Herman, M. and W. Koczkodaj (1996). "A Monte Carlo Study of Pairwise Comparison." Information Processing Letters 57(11): 25-29.

Ho, W. (2008). "Integrated analytic hierarchy process and its applications - A literature review." European Journal of Operational Research 186(1): 211-228.

Holder, R. (1990). "Some Comment on the Analytic Hierarchy Process." Journal of the Operational Research Society 41(11): 1073-1076.

Holder, R. (1991). "Response to Holder's Comments on the Analytic Hierarchy Process: Response to the Response." Journal of the Operational Research Society 42(10): 914918.

Hovanov, N., J. Kolari, et al. (2008). "Deriving weights from general pairwise comparisons matrices." Mathematical Social Sciences 55(2): 205-220.

Ishizaka, A. (2004). The Advantages of Clusters in AHP. 15th Mini-Euro Conference MUDSM. Coimbra.

Ishizaka, A. (2004). Développement d'un Système Tutorial Intelligent pour Dériver des Priorités dans l'AHP. Berlin, http://www.dissertation.de. 
Ishizaka, A., D. Balkenborg, et al. (2006). Influence of Aggregation and Preference Scale on Ranking a Compromise Alternative in AHP. Multidisciplinary Workshop on Advances in Preference Handling. Garda: 51-57.

Ishizaka, A. and M. Lusti (2004). "An Expert Module to Improve the Consistency of AHP Matrices." International Transactions in Operational Research 11(1): 97-105.

Ishizaka, A. and M. Lusti (2006). "How to derive priorities in AHP: a comparative study." Central European Journal of Operations Research 14(4): 387-400.

Ji, P. and R. Jiang (2003). "Scale transitivity in the AHP." Journal of the Operational Research Society 54(8): 896-905.

Johnson, C., W. Beine, et al. (1979). "Right-Left Asymmetry in an Eigenvector Ranking Procedure." Journal of Mathematical Psychology 19(1): 61-64.

Jones, D. and S. Mardle (2004). "A Distance-Metric Methodology for the Derivation of Weights from a Pairwise Comparison Matrix." Journal of the Operational Research Society 55(8): 869-875.

Kainulainen, T., P. Leskinen, et al. (2009). "A statistical approach to assessing interval scale preferences in discrete choice problems." Journal of the Operational Research Society 60(2): 252-258.

Karapetrovic, S. and E. Rosenbloom (1999). "A Quality Control Approach to Consistency Paradoxes in AHP." European Journal of Operational Research 119(3): 704-718.

Kumar, S. and O. Vaidya (2006). "Analytic hierarchy process: An overview of applications." European Journal of Operational Research 169(1): 1-29.

Kwiesielewicz, M. and E. van Uden (2004). "Inconsistent and Contradictory Judgements in Pairwise Comparison Method in AHP." Computers and Operations Research 31(5): 713-719.

Lane, E. and W. Verdini (1989). "A Consistency Test for AHP Decision Makers." Decision Sciences 20(3): 575-590.

Leskinen, P. and J. Kangas (2005). "Rank reversal in multi-criteria decision analysis with statistical modelling of ratio-scale pairwise comparisons." Journal of the Operational Research Society 56(7): 855-861.

Liberatore, M. and R. Nydick (2008). "The analytic hierarchy process in medical and health care decision making: A literature review." European Journal of Operational Research 189(1): 194-207.

Lin, C. (2007). "A Revised Framework for Deriving Preference Values from Pairwise Comparison Matrices." European Journal of Operational Research 176(2): 1145-1150.

Lootsma, F. (1989). "Conflict Resolution via Pairwise Comparison of Concessions." European Journal of Operational Research 40(1): 109-116.

Lootsma, F. (1993). "Scale sensitivity in the multiplicative AHP and SMART." Journal of Multi-Criteria Decision Analysis 2(2): 87-110.

Lootsma, F. (1996). "A model for the relative importance of the criteria in the Multiplicative AHP and SMART." European Journal of Operational Research 94(3): 467-476.

Ma, D. and X. Zheng (1991). 9/9-9/1 Scale Method of AHP. 2nd Int. Symposium on AHP. Pittsburgh 1: 197-202.

Millet, I. and T. Saaty (2000). "On the Relativity of Relative Measures-Accommodating both Rank Preservation and Rank Reversals in the AHP." European Journal of Operational Research 121(1): 205-212.

Millet, I. and B. Schoner (2005). "Incorporating negative values into the Analytic Hierarchy Process." Computers and Operations Research 32(12): 3163-73.

Omkarprasad, V. and K. Sushil (2006). "Analytic hierarchy process: an overview of applications." European Journal of Operational Research 169(1): 1-29. 
Peláez, P. and M. Lamata (2003). "A New Measure of Consistency for Positive Reciprocal Matrices." Computers \& Mathematics with Applications 46(12): 1839-1845.

Pérez, J. (1995). "Some comments on Saaty’s AHP." Management Science 41(6): 1091-1095. Pöyhönen, M., R. Hamalainen, et al. (1997). "An Experiment on the Numerical Modelling of Verbal Ratio Statements." Journal of Multi-Criteria Decision Analysis 6(1): 1-10.

Roy, B. (1996). Multicriteria Methodology for Decision Analysis. Dordrecht, Kluwer Academic Publishers.

Saaty, T. (1972). An eigenvalue allocation model for prioritization and planning. Working paper, Energy Management and Policy Center, University of Pennsylvania.

Saaty, T. (1977). "A scaling method for priorities in hierarchical structures." Journal of mathematical psychology 15(3): 234-281.

Saaty, T. (1980). The Analytic Hierarchy Process. New York, McGraw-Hill.

Saaty, T. (1986). "Axiomatic Foundation of the Analytic Hierarchy Process." Management Science 32(7): 841-855.

Saaty, T. (1990). "An Exposition of the AHP in Reply to the Paper "Remarks on the Analytic Hierarchy Process"." Management Science 36(3): 259-268.

Saaty, T. (1991). "Response to Holder's Comments on the Analytic Hierarchy Process." journal of the Operational Research Society 42(10): 909-929.

Saaty, T. (1994). "Highlights and critical points in the theory and application of the Analytic Hierarchy Process." European Journal of Operational Research 74(3): 426-447.

Saaty, T. (2003). "Decision-making with the AHP: Why is the Principal Eigenvector necessary?" European Journal of Operational Research 145(1): 85-91.

Saaty, T. (2006). "Rank from Comparisons and from Ratings in the Analytic Hierarchy/Network Processes." European Journal of Operational Research 168(2): 557-570.

Saaty, T. and E. Forman (1992). The Hierarchon: A Dictionary of Hierarchies. Pittsburgh, RWS Publications.

Saaty, T. and G. Hu (1998). "Ranking by Eigenvector Versus other Methods in the Analytic Hierarchy Process." Applied Mathematics Letters 11(4): 121-125.

Saaty, T. and M. Ozdemir (2003). "Negative Priorities in the Analytic Hierarchy Process." Mathematical and Computer Modelling 37(9-10): 1063-1075.

Saaty, T. and M. Takizawa (1986). "Dependence and Independence: from Linear Hierarchies to Nonlinear Networks." European Journal of Operational Research 26(2): 229-237.

Saaty, T. and L. Vargas (1984). "Comparison of Eigenvalue, Logarithmic Least Squares and Least Squares Methods in Estimating Ratios." Mathematical Modeling 5(5): 309-324.

Saaty, T. and L. Vargas (1984). "Inconsistency and Rank Preservation." Journal of Mathematical Psychology 28(2): 205-214.

Salo, A. and R. Hamalainen (1997). "On the Measurement of Preference in the Analytic Hierarchy Process." Journal of Multi-Criteria Decision Analysis 6(6): 309-319.

Shim, J. (1989). "Bibliography research on the analytic hierarchy process (AHP)." SocioEconomic Planning Sciences 23(3): 161-167.

Stam, A. and P. Duarte Silva (2003). "On Multiplicative Priority Rating Methods for AHP." European Journal of Operational Research 145(1): 92-108.

Stein, W. and P. Mizzi (2007). "The Harmonic Consistency Index for the Analytic Hierarchy Process." European Journal of Operational Research 177(1): 488-497.

Stillwell, W., D. von Winterfeldt, et al. (1987). "Comparing hierarchical and non-hierarchical weighting methods for eliciting multiattribute value models." Management Science 33(4): 442-450.

Temiz, N. and V. Tecim (2009). "The use of GIS and multi-criteria decision-making as a decision tool in forestry." ORInsight 22(2): 105-123. 
Triantaphyllou, E. (2001). "Two new cases of rank reversals when the AHP and some of its additive variants are used that do not occur with the Multiplicative AHP." Journal of Multi-Criteria Decision Analysis 10(1): 11-25.

Troutt, M. (1988). "Rank Reversal and the Dependence of Priorities on the Underlying MAV Function." Omega 16(4): 365-367.

Tummala, V. and Y. Wan (1994). "On the Mean Random Inconsistency Index of the Analytic Hierarchy Process (AHP)." Computers \& Industrial Engineering 27(1-4): 401-404.

Vargas, L. (1990). "An overview of the analytic hierarchy process and its applications." European Journal of Operational Research 48(1): 2-8.

Vargas, L. (1997). "Comments on Barzilai and Lootsma Why the Multiplicative AHP is Invalid: A Practical Counterexample." Journal of Multi-Criteria Decision Analysis 6(4): 169-170.

Wang, Y., K.-S. Chin, et al. (2009). "Aggregation of direct and indirect judgements in pairwise comparison matrices with a re-examination of the criticisms by Bana e Costa and Vansnick." Information Sciences 179(3): 329-337.

Wang, Y. and Y. Luo (2009). "On Rank Reversal in Decision Analysis." Mathematical and Computer Modelling 49(5-6): 1221-1229.

Webber, S., B. Apostolou, et al. (1996). "The sensitivity of the analytic hierarchy process to alternative scale and cue presentations." European Journal of Operational Research 96(2): 351-362.

Weber, M., F. Eisenführ, et al. (1988). "The Effects of Spitting Attributes on Weights in Multiattribute Utility Measurement." Management Science 34(4): 431-445.

Zahedi, F. (1986). "The analytic hierarchy process: a survey of the method and its applications." Interface 16(4): 96-108. 